\title{
Analytical pyrolysis with in-situ silylation, Py (HMDS)-GC/MS, for the chemical characterization of archaeological and historical amber objects
}

\author{
Maria Perla Colombini", Erika Ribechini, Marco Rocchi and Paola Selleri
}

\begin{abstract}
Introduction: An optimised analytical technique based on pyrolysis coupled with gas chromatography/mass spectrometry (Py-GC/MS) and derivatisation in situ with hexamethyldisilazane (HMDS) was used to study several archaeological and artistic amber objects. The aim was to verify the authenticity of the objects and to provide historical information regarding the geographical origin of the ambers, and thus reveal the trade routes between different ancient civilizations.
\end{abstract}

Results: Py-GC/MS using HMDS as a silylating agent enabled us not only to identify the geographical origin of the archaeological and artistic ambers as succinites, but also highlighted the degradation of amber objects revealing a lower abundance of free diterpenes on the surface.

Conclusion: This work demonstrates the capability of Py-GC/MS with silylation in situ to identify the geographical origin of archaeological ambers and to provide crucial information regarding their degradation process. The porous and rough appearance of the outer layer can be correlated with the higher lixiviation and to the evaporation of free diterpenes from the surface. The knowledge of the amber degradation mechanisms is crucial to select proper conservation-restoration methods.

Keywords: Amber, Succinite, Analytical pyrolysis, In situ silylation, Archaeometry

\section{Introduction}

Since ancient times the unique physical properties of amber have been exploited in the production of jewels, tools, ornaments, and works of art. Amber belongs to the class of fossil resins and is formed from plant deposits by the evaporation of volatile components, maturation, and polymerization reactions over a geological timescale. In Europe, the largest known deposit of amber deriving from conifers is found in northern Europe, mostly, in the Baltic area. This fossil resin is thus called Baltic amber and represents a specific subset of amber containing up to $8 \%$ by weight of succinic acid [1-3]. However, deposits of ambers of different geological eras and botanical origins can also be found all over Europe including Italy, Spain, Germany and Romania, and in the other part of the World, such us Canada, Alaska, Brasil. Amber objects are an important

\footnotetext{
* Correspondence: perla@dcci.unipi.it

Department of Chemistry and Industrial Chemistry, University of Pisa, via Risorgimento 35, 56126, Pisa, Italy
}

part of our cultural and ethnographic heritage, and studying them reveals the history, technology, rituals and trade routes of the past. The determination of its chemical composition can be used for an easy identification of amber among other fossil resins and copals and to distinguish it from imitations, widely diffused on the market.

However, the study of ambers represents a real challenge for analytical chemistry. This is mainly due to the relatively small amounts of samples available from artworks, to the high degree of polymerization, to the complex mixture of very similar organic compounds, which are characterized by a wide variety of molecular weights, which make up the fossil resins, and to the presence of possible degradation products.

A variety of physical and chemical techniques have been employed in the identification and characterisation of ambers $[1,2,4]$. In particular, spectroscopic analyses including FT-IR, FT-Raman and NMR have been widely exploited [2,5-19]. Such analytical approaches use bulk analysis to examine ambers and to obtain information 
on the botanical origins of archaeological findings. In addition, due to the high molecular weight/polymeric nature of ambers, some researchers have used analytical pyrolysis coupled with GC/MS systems (Py-GC/MS) $[1,2,5,20-23]$. When analytical pyrolysis is used, the chemical composition of the sample is reconstructed on the basis of an interpretation of the molecular profile of the thermal degradation products of the original components, and on the recognition of specific molecular markers or molecular patterns, which give characteristic fingerprints of the pyrolysed material. In fact, the classification [1] of ambers used in almost all of the scientific literature, is based on the structure of the resinite polymeric matrix, as determined by pyrolysis-gas chromatography-mass spectrometry $[20,24]$. As with many organic natural substances, under pyrolysis ambers produce low volatile molecules that contain polar functionalities, which are not efficiently separated by GC.

The most common approach to overcome this kind of problem is to use thermally assisted derivatisation reactions. The use of derivatisation reagents that transform the polar pyrolysis products into less polar and more volatile compounds, improves the analytical performance and the detection limits of the technique. Tetramethyl ammonium hydroxide (TMAH) allows hydrolysis and methylation to be obtained simultaneously and is thus widely used derivatisation reagent $[1,20]$. Recently, silylating reactions using hexamethyldisilazane (HMDS) have been proposed as an alternative in the analysis of ambers $[21,23,25]$. HMDS proved its potential with respect to the strongly alkaline TMAH reagent. Actually, the main limitations of this derivatizing reaction are related to the occurring of secondary reactions: particularly, decarboxylation reactions undergone by carboxylic acids and the formation of dehydration products and other by-products produce pyrograms of difficult interpretation. Moreover, TMHA can also induce decomposition of the stationary phase of the gas chromatographic column [26,27].

In addition, thermal desorption-gas chromatography coupled with mass spectrometry detection (TD-GC/MS) has been used to investigate the volatile compound fractions from ambers with a focus on Romanite (Romanian amber) and Succinite from several regions in Northern Europe and Baltic area $[28,29]$.

This paper presents a study on archaeological and artistic amber objects using an optimised analytical technique based on pyrolysis coupled with gas chromatography/ mass spectrometry (Py-GC/MS) and derivatisation in situ with hexamethyldisilazane (HMDS). The analytical approach was applied to several samples in order to:

- verify the authenticity of the object

- provide historical information regarding the botanic and eventually geographical origin of the ambers, and thus reveal trade routes between ancient civilizations

- understand the degradation of the resin artworks.

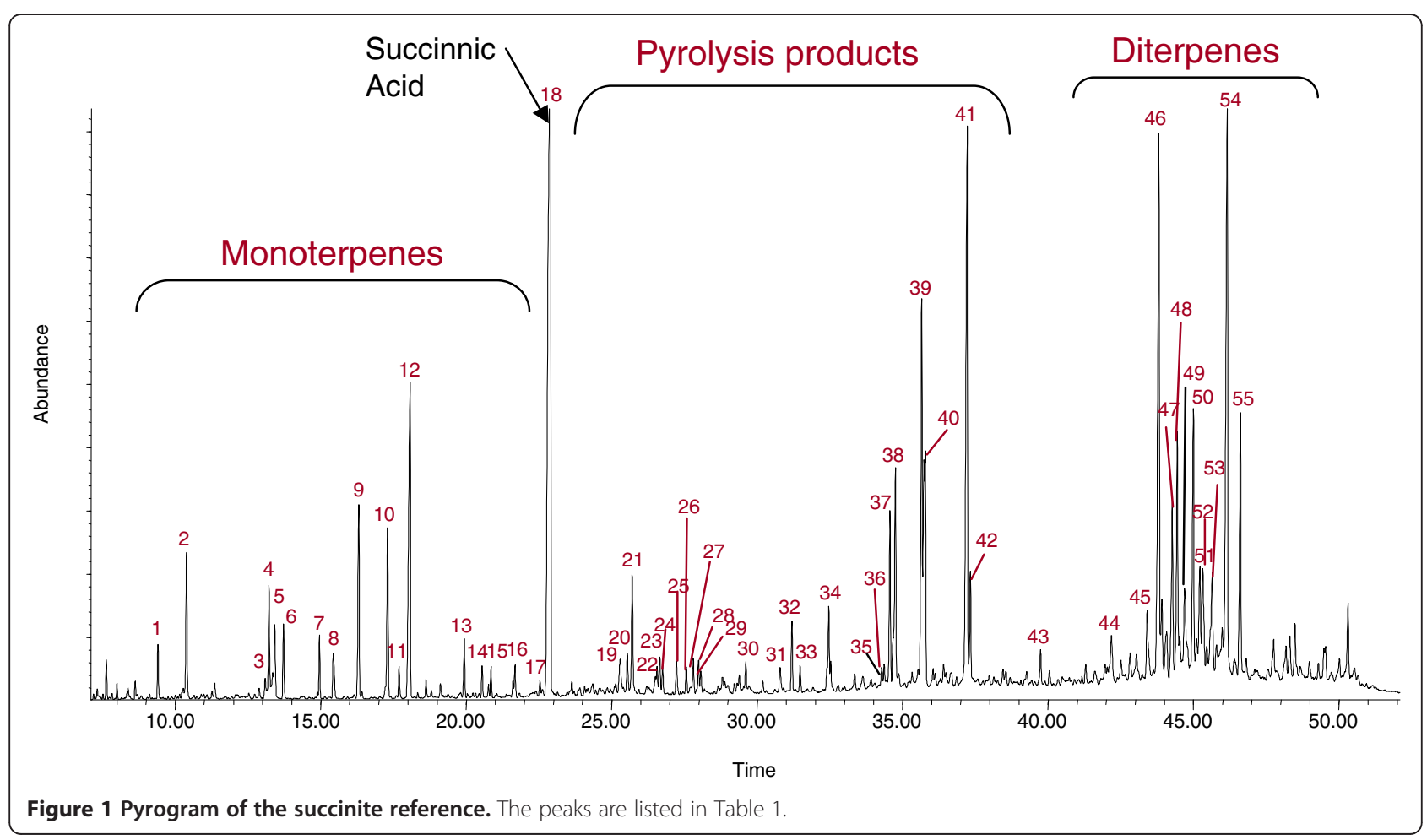


Table 1 The pyrolysis products of the succinite reference, and of the most representative samples from the three different sites (Atri, Novilara, Apollonia) and from the Fountain

\begin{tabular}{|c|c|c|c|c|c|c|c|}
\hline Number of peak & Name of the compound & M.W. & $\begin{array}{l}\text { Succinite } \\
\text { reference }\end{array}$ & Atri 35 & $\begin{array}{l}\text { Spurious } \\
\text { Novilara }\end{array}$ & $\begin{array}{l}\text { Disc Apollonia } \\
\text { (surface sample) }\end{array}$ & Fountain \\
\hline 1 & 3-Carhene & 136 & $\checkmark$ & $\checkmark$ & $\checkmark$ & $\checkmark$ & $\checkmark$ \\
\hline 2 & Camphene & 136 & $\checkmark$ & $\checkmark$ & $\checkmark$ & $\checkmark$ & $\checkmark$ \\
\hline 3 & 1,2,3 trimethylbenzene & 120 & $\checkmark$ & - & $\checkmark$ & $\checkmark$ & - \\
\hline 4 & m-Cymene & 134 & $\checkmark$ & - & $\checkmark$ & $\checkmark$ & $\checkmark$ \\
\hline 5 & unknown & $154 ?$ & $\checkmark$ & - & - & - & $\checkmark$ \\
\hline 6 & p-Cymene & 134 & $\checkmark$ & $\checkmark$ & $\checkmark$ & $\checkmark$ & $\checkmark$ \\
\hline 7 & Propanoic acid 2TMS & 234 & $\checkmark$ & $\checkmark$ & $\checkmark$ & $\checkmark$ & $\checkmark$ \\
\hline 8 & L-Fenchone & 152 & $\checkmark$ & $\checkmark$ & $\checkmark$ & $\checkmark$ & $\checkmark$ \\
\hline 9 & Fenchol & 154 & $\checkmark$ & $\checkmark$ & $\checkmark$ & $\checkmark$ & $\checkmark$ \\
\hline 10 & Camphor & 152 & $\checkmark$ & $\checkmark$ & $\checkmark$ & $\checkmark$ & $\checkmark$ \\
\hline 11 & Isoborneol & 152 & $\checkmark$ & $\checkmark$ & $\checkmark$ & & $\checkmark$ \\
\hline 12 & Borneol & 154 & $\checkmark$ & $\checkmark$ & $\checkmark$ & $\checkmark$ & $\checkmark$ \\
\hline 13 & Borneol (TMS) & 226 & $\checkmark$ & $\checkmark$ & $\checkmark$ & $\checkmark$ & $\checkmark$ \\
\hline 14 & Benzoic acid (TMS) & 194 & $\checkmark$ & $\checkmark$ & $\checkmark$ & $\checkmark$ & $\checkmark$ \\
\hline 15 & unknown & $226 ?$ & $\checkmark$ & $\checkmark$ & $\checkmark$ & $\checkmark$ & $\checkmark$ \\
\hline 16 & unknown & $178 ?$ & $\checkmark$ & $\checkmark$ & $\checkmark$ & $\checkmark$ & $\checkmark$ \\
\hline 17 & unknown & $178 ?$ & $\checkmark$ & - & $\checkmark$ & $\checkmark$ & $\checkmark$ \\
\hline 18 & Succinic acid (2TMS) & 262 & $\checkmark$ & $\checkmark$ & $\checkmark$ & $\checkmark$ & $\checkmark$ \\
\hline 19 & unknown & 204 & $\checkmark$ & - & $\checkmark$ & $\checkmark$ & $\checkmark$ \\
\hline 20 & unknown & & $\checkmark$ & - & $\checkmark$ & $\checkmark$ & $\checkmark$ \\
\hline 21 & $\begin{array}{l}(1 \mathrm{~S}, 4 \mathrm{aS})-1,4 \mathrm{a}, 5,6 \text {-tetramethyl- } \\
\text { 1,2,3,4,4a,5,8,8a-octahydronaphtalene }\end{array}$ & 192 & $\checkmark$ & $\checkmark$ & $\checkmark$ & $\checkmark$ & $\checkmark$ \\
\hline 21 & $\begin{array}{l}\text { (1R, 4aS)-1,4a,6-trimethyl- 1,2,3,4,4a,5,8,8a- } \\
\text { octahydro 5- methylene naphtalene }\end{array}$ & 190 & $\checkmark$ & $\checkmark$ & $\checkmark$ & $\checkmark$ & $\checkmark$ \\
\hline 22 & $\begin{array}{l}\text { (1S, 4aS)-1, 4a, 5, 6-tetramethyl- } \\
1,2,3,4,4 a, 5,8,8 a-\text {-octahydronaphtalene }\end{array}$ & 192 & $\checkmark$ & $\checkmark$ & $\checkmark$ & $\checkmark$ & $\checkmark$ \\
\hline 23 & $\begin{array}{l}\text { (1R, 4aS)-1,4a,6-trimethyl- 1,2,3,4,4a,5,8,8a- } \\
\text { octahydro 5- methylene naphtalene }\end{array}$ & 190 & $\checkmark$ & - & - & $\checkmark$ & $\checkmark$ \\
\hline 24 & unknown & 202 & $\checkmark$ & - & $\checkmark$ & $\checkmark$ & $\checkmark$ \\
\hline 25 & 1,2,3,4-tetrahydro-1,6,8-trimethyl naphthalene & 174 & $\checkmark$ & - & $\checkmark$ & $\checkmark$ & $\checkmark$ \\
\hline 26 & $\begin{array}{l}\text { (4aS, } 8 \text { aS)- 1,1,4a,5,6-penthamethyl } \\
1,2,3,4,4 a, 7,8,8 a,-o c t a h y d r o-I-n a p h t h a l e n e\end{array}$ & 206 & $\checkmark$ & - & $\checkmark$ & $\checkmark$ & $\checkmark$ \\
\hline 27 & $\begin{array}{l}\text { (4aR, 8aR) 1,1,4a, 6, tetramethyl-5-methilene } \\
1,2,3,4,4 a, 5,8,8 \mathrm{a}, \text { octahydroNapthalene }\end{array}$ & 204 & $\checkmark$ & $\checkmark$ & $\checkmark$ & $\checkmark$ & $\checkmark$ \\
\hline 28 & unknown & 202 & $\checkmark$ & - & - & $\checkmark$ & $\checkmark$ \\
\hline 29 & unknown & & $\checkmark$ & - & - & - & $\checkmark$ \\
\hline 30 & unknown & $204 ?$ & $\checkmark$ & - & $\checkmark$ & - & $\checkmark$ \\
\hline 31 & unknown & & $\checkmark$ & $\checkmark$ & $\checkmark$ & $\checkmark$ & $\checkmark$ \\
\hline 32 & unknown & & $\checkmark$ & $\checkmark$ & $\checkmark$ & $\checkmark$ & $\checkmark$ \\
\hline 33 & unknown & & $\checkmark$ & $\checkmark$ & $\checkmark$ & $\checkmark$ & $\checkmark$ \\
\hline 34 & $\begin{array}{l}\text { 1,4 a,6,trimethyl-1,2,3,4,4,a,5,8,8a, } \\
\text { octahydronaphtalene-1-carboxylic acid (TMS) }\end{array}$ & 294 & $\checkmark$ & $\checkmark$ & $\checkmark$ & $\checkmark$ & $\checkmark$ \\
\hline 34 & $\begin{array}{l}\text { 1,4 a,6,trimethyl-1,2,3,4,4,a, }, 7,8,8 \mathrm{a} \\
\text { octahydronaphtalene-1-carboxylic acid (TMS) }\end{array}$ & 294 & $\checkmark$ & - & $\checkmark$ & $\checkmark$ & $\checkmark$ \\
\hline 35 & $\begin{array}{l}\text { 1,4 a, 5, 6, tetramethyl- 1,2,3,4,4a,7,8,8a, } \\
\text {-octahydronaphtalene-1-methanol (TMS) }\end{array}$ & 294 & $\checkmark$ & - & $\checkmark$ & $\checkmark$ & $\checkmark$ \\
\hline 36 & $\begin{array}{l}\text { 1,4 a, 6, trimethyl-5-methylene-1,2,3,4,4a,5,8,8a, } \\
\text {-octahydronaphtalene-1-methanol (TMS) }\end{array}$ & 292 & $\checkmark$ & - & $\checkmark$ & - & $\checkmark$ \\
\hline
\end{tabular}


Table 1 The pyrolysis products of the succinite reference, and of the most representative samples from the three different sites (Atri, Novilara, Apollonia) and from the Fountain (Continued)

\begin{tabular}{|c|c|c|c|c|c|c|c|}
\hline 37 & unknown & & $\checkmark$ & $\checkmark$ & $\checkmark$ & $\checkmark$ & $\checkmark$ \\
\hline 38 & unknown & & $\checkmark$ & $\checkmark$ & $\checkmark$ & $\checkmark$ & $\checkmark$ \\
\hline 39 & unknown & & $\checkmark$ & $\checkmark$ & $\checkmark$ & $\checkmark$ & $\checkmark$ \\
\hline 40 & unknown & & $\checkmark$ & - & $\checkmark$ & - & $\checkmark$ \\
\hline 41 & unknown & & $\checkmark$ & $\checkmark$ & $\checkmark$ & $\checkmark$ & $\checkmark$ \\
\hline 42 & unknown & & $\checkmark$ & - & - & $\checkmark$ & - \\
\hline$\overline{43}$ & Palmitic acid (TMS) & 328 & $\checkmark$ & - & - & $\checkmark$ & $\checkmark$ \\
\hline 44 & unknown & & $\checkmark$ & - & $\checkmark$ & - & - \\
\hline 45 & unknown & 374 & $\checkmark$ & . & - & - & - \\
\hline 46 & Pimaric acid (TMS) & 374 & $\checkmark$ & $\checkmark$ & $\checkmark$ & - & $\checkmark$ \\
\hline 47 & Isopimaric acid (TMS) & 374 & $\checkmark$ & $\checkmark$ & - & - & $\checkmark$ \\
\hline 48 & Unknown diterpene & 376 & $\checkmark$ & - & - & - & - \\
\hline 49 & Unknown diterpene & 374 & $\checkmark$ & - & - & - & - \\
\hline 50 & Unknown diterpene & 374 & $\checkmark$ & - & $\checkmark$ & - & - \\
\hline 51 & Unknown diterpene & 374 & $\checkmark$ & - & - & - & - \\
\hline 52 & Unknown diterpene & 374 & $\checkmark$ & - & - & - & - \\
\hline 53 & Unknown diterpene & 372 & $\checkmark$ & - & - & - & - \\
\hline 54 & Dehydroabietic acid (TMS) & 372 & $\checkmark$ & $\checkmark$ & - & - & $\checkmark$ \\
\hline 55 & Abietic acid (TMS) & 374 & $\checkmark$ & $\checkmark$ & - & - & - \\
\hline
\end{tabular}

The chemical characterisation of the archaeological and artistic samples was carried out for the following objects: a fibula and earrings from a tomb of the Novilara necropolis near Pesaro Urbino (Italy), and a necklace pendant from the excavation of a Picean tomb in Atri (Teramo, Italy), from the 7th century BC (Museo Archeologico Nazionale in Florence); an amber disc found in the Bonjaket archaeological site in Apollonia (Albania) from the 6th century $\mathrm{BC}$; and the Amber fountain (17th century) at Museo degli Argenti (museum of silver) in Florence, Italy.

Interestingly, all the artistic objects were made from Baltic amber and differences in the conservation of the superficial layers are noted and discussed.

\section{Results and discussion}

Our procedure is based on pyrolysis coupled with gas chromatography/mass spectrometry (Py-GC/MS) and derivatisation in situ with hexamethyldisilazane (HMDS). Its reproducibility was tested on a reference succinite (opaque yellow, Natural History Museum, Milan) and applied to a large set of geological succinites to verify the robustness of the procedure.

The procedure was optimized by repeating the pyrolysis on the reference succinite at different temperatures within a range of 450 to $600^{\circ} \mathrm{C}$. The pyrograms resulting from the various temperatures showed a similar composition, only differing in the relative abundance of compounds. The main peak always corresponded to succinic
Table 2 Archaeological and artistic samples

\begin{tabular}{|c|c|c|}
\hline Name Sample & Appearance & $\begin{array}{l}\text { Archaeological } \\
\text { site / Museum }\end{array}$ \\
\hline Atri necklace 35 & Red-brown & "la Pretara" Atri (Italy) \\
\hline Atri necklace 68 & Orange dark & "la Pretara" Atri (Italy) \\
\hline Atri necklace 79 & Orange dark & "la Pretara" Atri (Italy) \\
\hline Atri necklace 80 & Orange & "la Pretara" Atri (Italy) \\
\hline Apollonia disc & Orange & $\begin{array}{l}\text { Bonjaket Apollonia } \\
\text { (Albany) }\end{array}$ \\
\hline Novilara da cont 37 & Orange opaque & $\begin{array}{l}\text { Novilara Pesaro Urbino } \\
\text { (Italy) }\end{array}$ \\
\hline Novilara fibula 42 & Orange opaque & $\begin{array}{l}\text { Novilara Pesaro Urbino } \\
\text { (Italy) }\end{array}$ \\
\hline Novilara earring 43 & Yellow opaque & $\begin{array}{l}\text { Novilara Pesaro Urbino } \\
\text { (Italy) }\end{array}$ \\
\hline Novilara earring 44 & Yellow orange opaque & $\begin{array}{l}\text { Novilara Pesaro Urbino } \\
\text { (Italy) }\end{array}$ \\
\hline Novilara earring 45 & Yellow orange & $\begin{array}{l}\text { Novilara Pesaro Urbino } \\
\text { (Italy) }\end{array}$ \\
\hline Novilara earring 46 & Orange dark & $\begin{array}{l}\text { Novilara Pesaro Urbino } \\
\text { (Italy) }\end{array}$ \\
\hline Novilara small fibula & Light Yellow & $\begin{array}{l}\text { Novilara Pesaro Urbino } \\
\text { (Italy) }\end{array}$ \\
\hline Novilara spurious & varied & $\begin{array}{l}\text { Novilara Pesaro Urbino } \\
\text { (Italy) }\end{array}$ \\
\hline Fountain fragment 1 & Light Yellow & $\begin{array}{l}\text { Museum of Silver, } \\
\text { Florence (Italy) }\end{array}$ \\
\hline Fountain fragment 2 & Orange brown & $\begin{array}{l}\text { Museum of Silver, } \\
\text { Florence (Italy) }\end{array}$ \\
\hline
\end{tabular}


acid; with the increasing temperature of pyrolysis, the relative abundance of mono and diterpenes decreased, due to thermal decomposition, while the amount of degradation products of the polymeric matrix increased. The optimal temperature of pyrolysis was found to be $480^{\circ} \mathrm{C}$ with a pyrolyser interface at $280^{\circ} \mathrm{C}$. Using these conditions (see the experimental section), the pyrogram of the reference succinite is shown in Figure 1.

This analysis revealed the presence of mono-, sesquiand diterpenoids together with succinic acid. In addition, several bicyclic pyrolysis degradation products were observed. These compounds are related to the polylabdanic structure of the polymeric fraction of the succinite: the bicycle products corresponding to peaks no. $21 \div 42$ in Figure 1 and Table 1 are derived from the pyrolysis of communic acid and communol. Actually, according to the classification proposed by Anderson [1], the succinite is defined as a class $I$ a resinite containing succinic acid and polymers of labdanoid diterpenes having a regular configuration such as communic acid and communol. Table 1 reports the identification of the main pyrolysis products. The reproducibility of the method at $480^{\circ} \mathrm{C}$ was tested by analysing the same sample of succinite in triplicate. Peak areas of the pyrolysis products were measured, and the data for three replicated analyses averaged and expressed as percentages of the total. The relative standard deviation (\%RSD) for relative peak areas of the peaks reported in Table 1 is between $15-20 \%$. This accounts for the sampling in different areas of the same geological amber, which exhibited an expected change in its chemical composition.

The analytical procedure was verified on the other 19 reference geological succinites from various museums. For all the samples under analysis, the main peak corresponds to succinic acid. The pyrograms are quite similar in terms of the identified compounds reported in Table 1; only the relative abundances differ slightly. Considering the different origin and the geological formation of these succinites (different maturities due to diagenetic influences and chemical transformations occurred during fossilization), the difference in relative abundances seems quite reasonable. Thus, the procedure gives a sound fingerprint of the succinites and the possibility of reliably recognizing a Baltic amber.

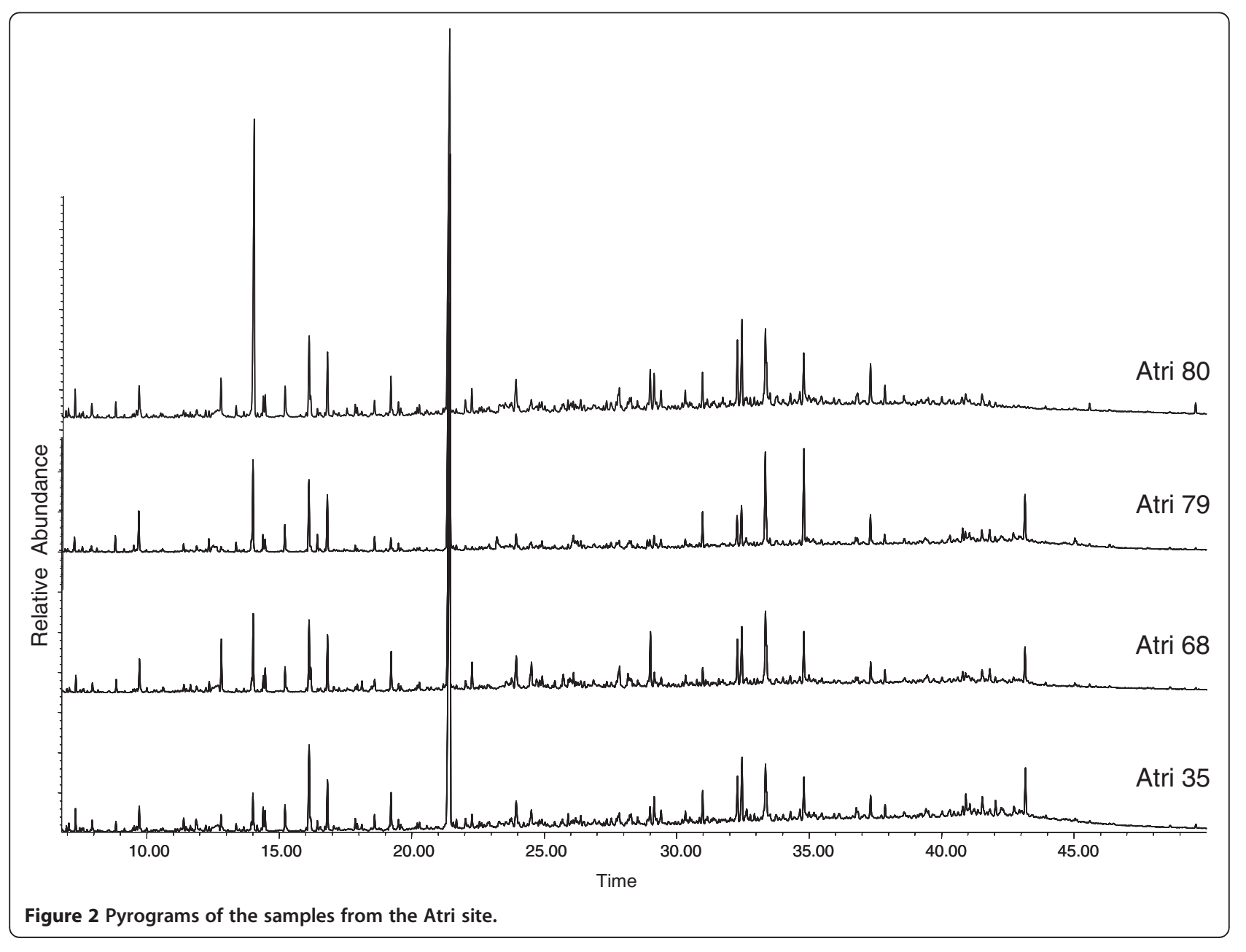


In the following section, the results of the archaeological and historical samples, listed in Table 2, are reported.

\section{Novilara/Atri}

\section{Samples from Atri}

All the samples from the tomb in Atri gave quite similar pyrograms (Figure 2). A comparison of chromatograms of the samples (Atri 80, Atri 79, Atri 68, Atri 35) with the reference geological succinite showed that for all the Atri samples, the pyrolysis pattern is typical of succinite coming from the Baltic region (Table 1). However, the archaeological ambers from the Atri site were poorer in terpenoids, such as abietic and dehydroabietic acids, compared to the geological amber reference. Since such species form the soluble parts of ambers, they may be gradually lost due to lixiviation while underground, though a surface oxidation of ambers may also have occurred.

\section{Samples from Novilara}

The chromatograms of all the samples from the Novilara tomb are shown in Figure 3 and were quite similar to those obtained for the Atri tomb samples. A comparison of the chromatograms with the reference succinite (Table 1) showed that both the fibula and the earrings were made from Baltic amber. In fact, the analysis revealed a remarkable content of succinic acid, mono- and sesqui-terpens. Anyway, diterpenes with abietane structure, such as levopimaric acid, pimaric acid and dehydroabietic acid were found in a lower abundance. The samples from Novilara and Atri tombs showed a similar degradation with an important loss of free diterpenes.

\section{Sample from Apollonia}

Figure 4 shows two pyrograms obtained from the analysis of the disk from the archaeological site in Apollonia (Albany): the object was sampled not only on the coarse

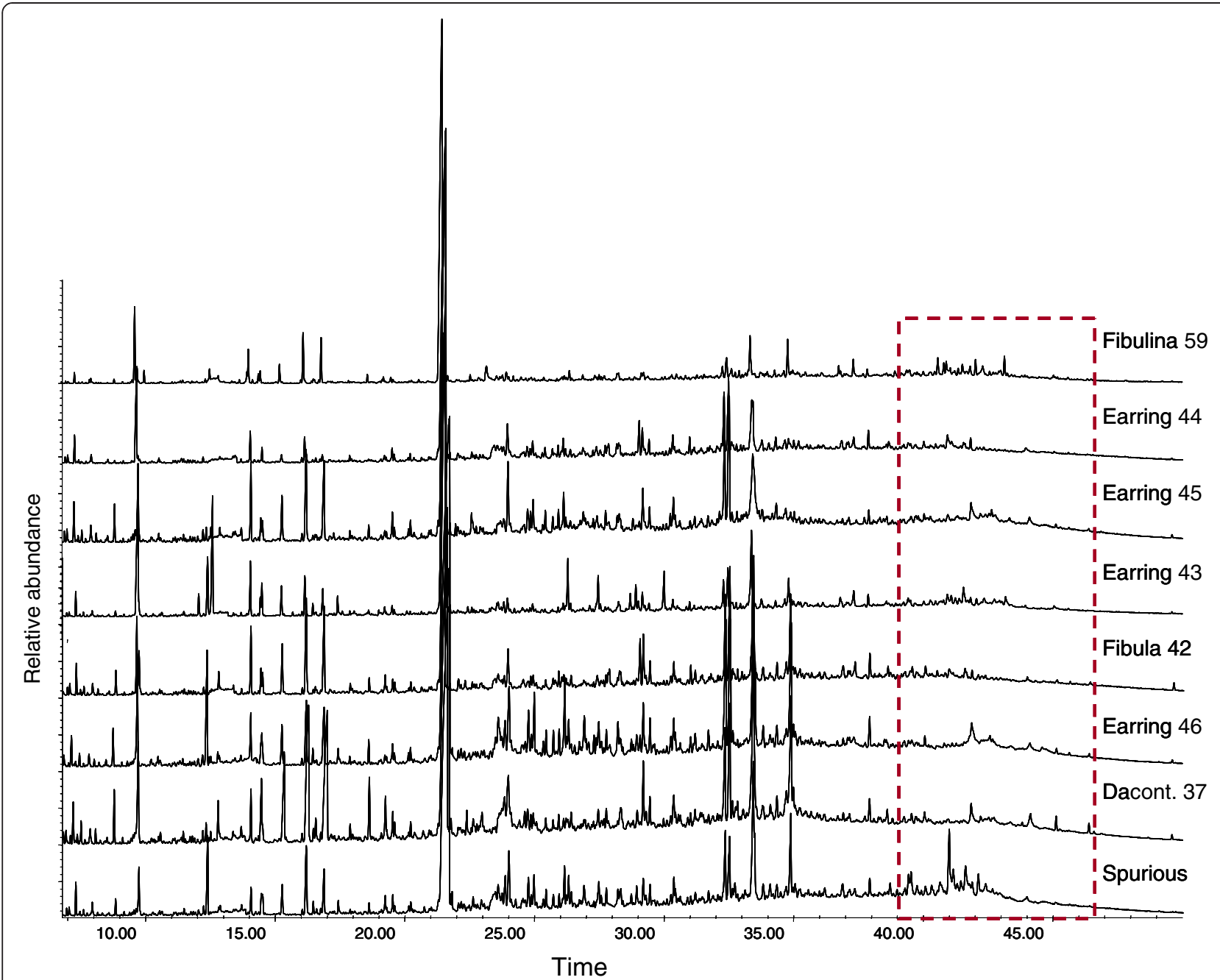

Figure 3 Pyrograms of the samples from Novilara. The dotted line highlights the diterpenes area between 40-50 minutes. 


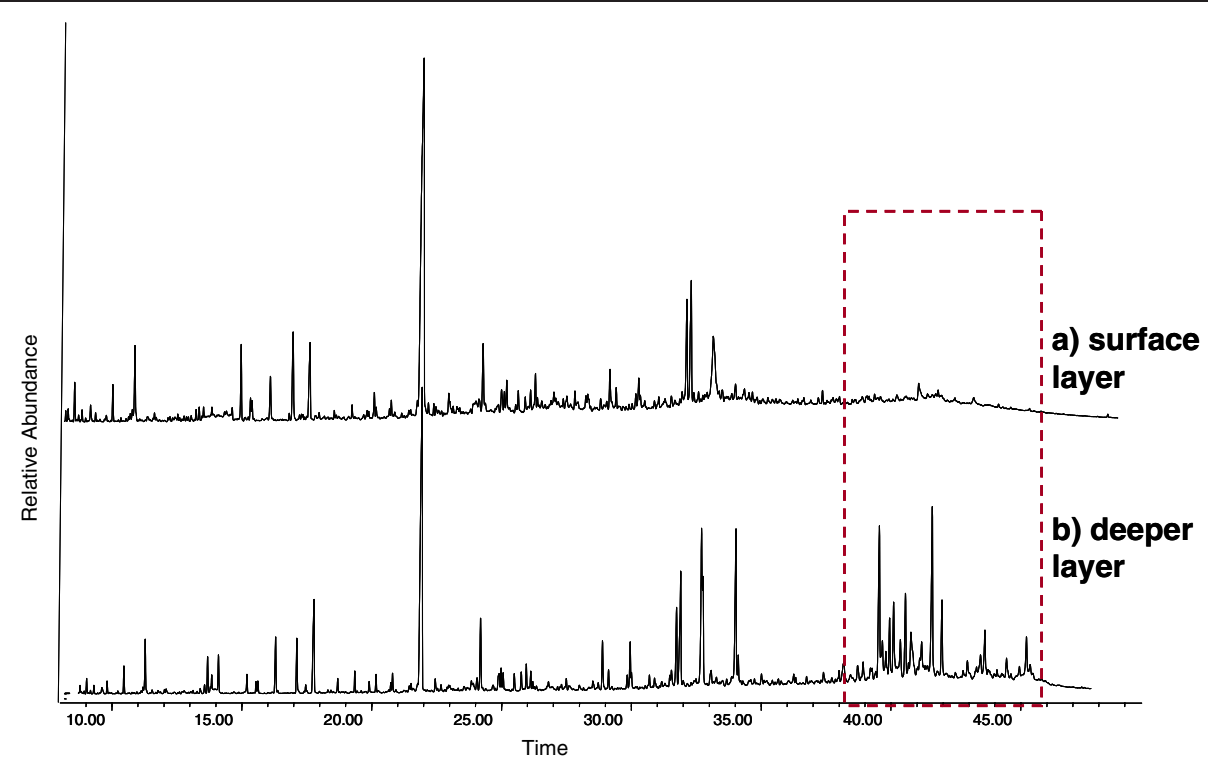

Figure 4 Comparison between the two pyrograms of the disc from the Apollonia site. Pyrogram a) corresponds to the external sample, pyrogram b) corresponds to the bulk area. The dotted line highlights the part of the diterpenes between 40-50 minutes.

surface but also in a point where the surface was scratched during the excavation, thus giving access to the bulk. The Py-GC/MS analysis revealed the presence of succinic acid along with several mono-, sesqui- and di-terpenes (Table 1). A comparison of these results with those obtained by analysing geological reference succinite confirmed that the archaeological samples were indeed Baltic amber.
In addition, the pyrogram of the surface layer exhibited a depletion of free diterpenes in the region 40-50 min, while the fingerprint of diterpene peaks of the inner layer was comparable to that of the reference succinite. This result indicates a substantial loss of diterpens from the external layer. This loss affected a few microns of the depth and could be responsible for the porous, rough and opaque appearance, due to a change in the macromolecular structure.

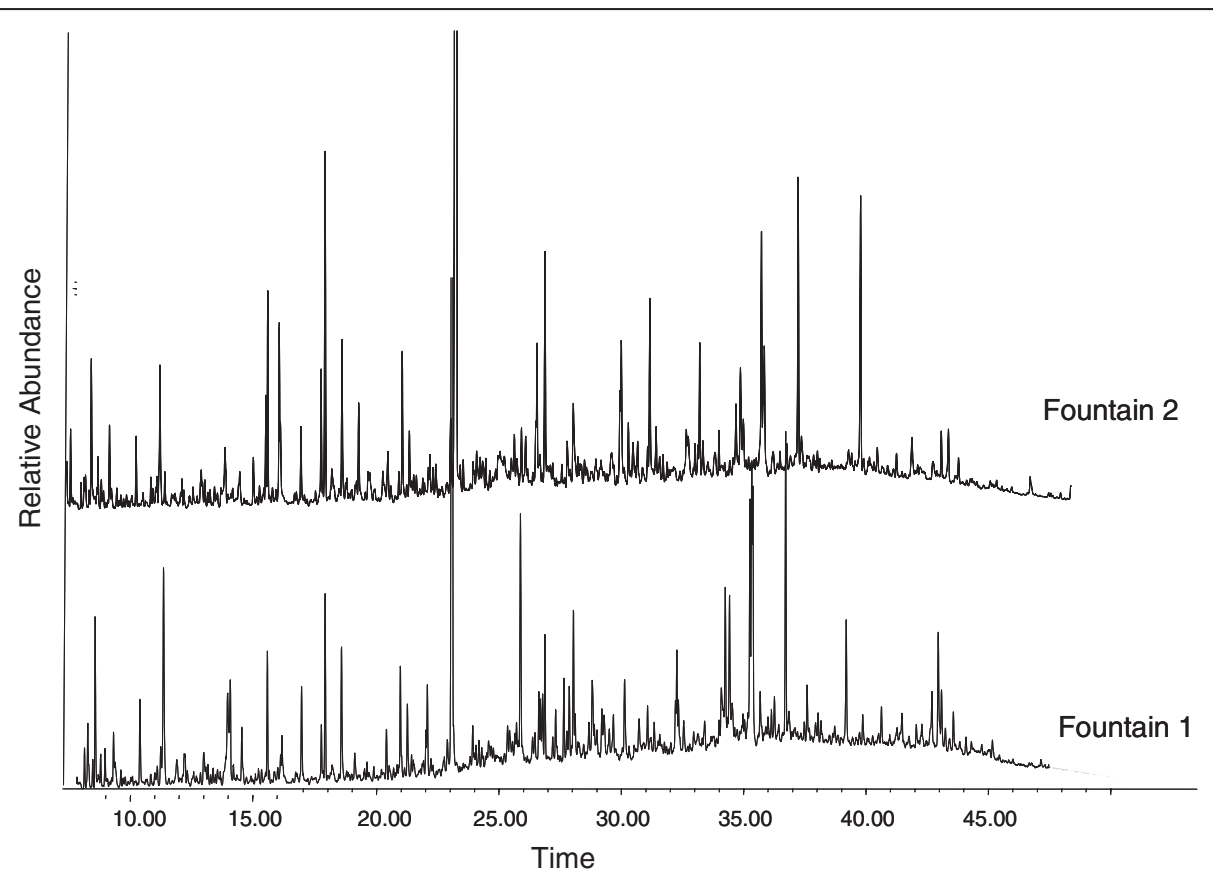

Figure 5 Pyrograms of the two samples of the Fountain. 


\section{Amber fountain}

Two fragments, with very different appearances, were found detached from the Amber Fountain in Florence, and were analysed. Figure 5 shows the pyrograms of the two fragments (the peak identification is reported in Table 1): they are well superimposed, and both correspond to the fingerprint of Baltic amber.

Also in this case the samples were poor in terpenoids compared to the reference succinite. Thus it is possible that the two fragments belong to the surface of the artifact and not to a detached material applied in a restoration work, as previously suggested. Due to exposure to the specific humidity and light levels of the environment, the two amber flakes may have changed color turning to light yellow and orange, respectively. This may have also caused a change in the internal structure leading to the occurrence of cracks and detachments.

\section{Conclusions}

We believe that this work demonstrates that gas chromatography/mass spectrometry (Py-GC/MS) and derivatisation in situ with hexamethyldisilazane (HMDS) are particularly suited for the characterization of ambers. This approach enabled us to identify the geographical origin of the archaeological ambers. The archaeological samples from the Italian sites were found to consist of Succinite, thus ruling out any possible Italian origin of the ambers (such as Simetite from Sicily or ambers from the Dolomites or Apennines) which have been shown to contain small or non-detectable quantities of succinic acid [30].

The determination of the geographical origin of amber is historically significant, because it confirms the existence

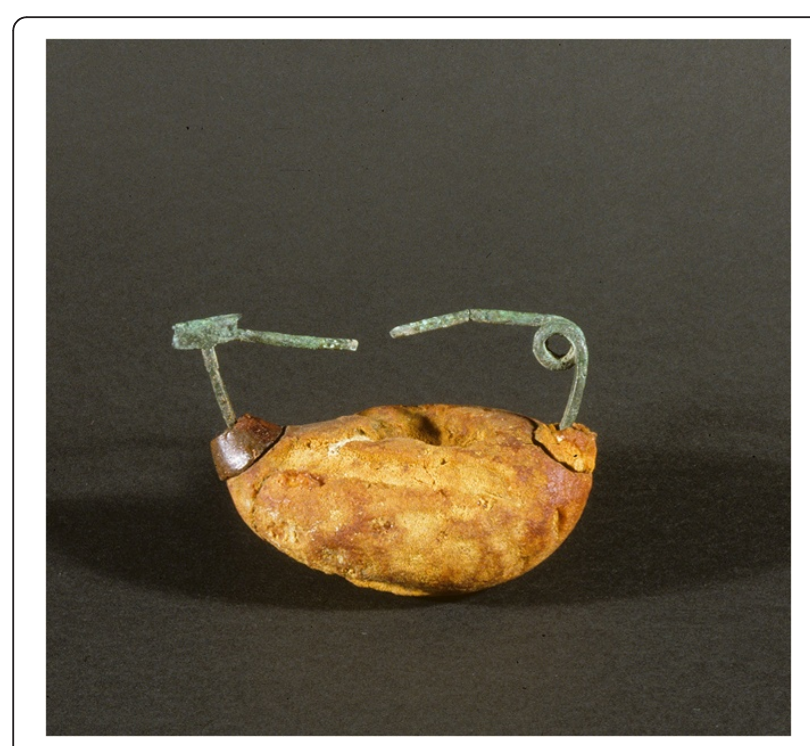

Figure 6 The Fibula 42 from the tomb of the Novilara necropolis near Pesaro Urbino (Italy), dating to 7th century BC. of commercial exchanges between countries in the Baltic and Mediterranean (the so-called "Amber Route"). The first written record of the "Amber Route" dates back to Pliny the Elder (23-79 AD), and Baltic amber was involved in a long-distance trade throughout Europe and Asia, beginning perhaps as long ago as the Mesolithic period. Thus, the identification of Baltic amber rather than the locally-available amber in these archaeological works of art is indicative of long-distance trade in the 7th century BC: inhabitants of southern Italy were using the "Amber route" to buy the resin preferring succinite instead of Italian amber to produce their works of art. Aesthetic reasons or, more probably, the greater availability of Baltic amber favoured trade with the Baltic area.

In addition our approach provided crucial information regarding the degradation process that takes place over the course of time. Weathered amber is very often covered by a "cortex" or "crust" making its surface coarse or uneven: the chromatograms of the archaeological and artistic samples revealed a lower concentration of diterpenes on the

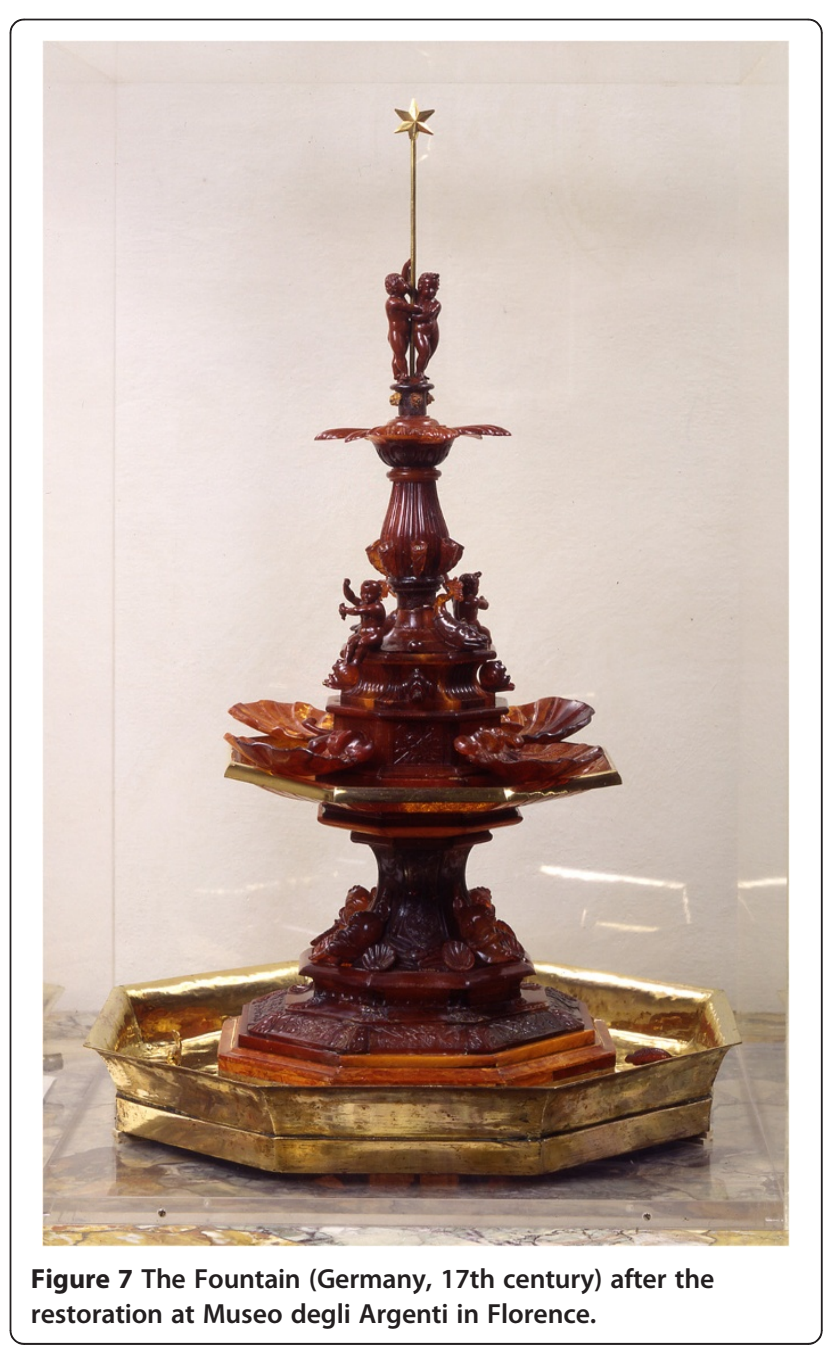


surface. This is due to the higher evaporation or, in the case of periods underground, to lixiviation of free diterpenoids from the surface, which in turn seem responsible for the porous and rough appearance of the outer layer.

With regard to the Fountain, the analysis provided an authentication of the two fragments that were found while moving the artwork: this ruled out the hypothesis of the fragments being restoration materials, for which no documentation was available. A reduction in the free diterpenoids was also found, which was related to the surface degradation of the samples.

It is thus possible to conclude that the outer layer of the Baltic amber analysed objects was affected by environmental exposure, showing a porous, rough and opaque surface as a consequence of a change in the macromolecular structure.

The knowledge of such a degradation may help in finding new restoration approaches and mitigation methods for amber conservation.

\section{Experimental \\ Material and methods \\ Samples}

Reference samples Twenty succinite samples from the Eocene and Miocene deposits in Germany, Ukraine, Russia and Poland were provided by three museums: the Musuem of Archeology and Natural Sciences (Montecchio Maggiore, Vicenza, Italy), the Museum of the Earth of the Polish Academy of Sciences (Warsaw, Poland), the Natural History Museum (Milan, Italy). These samples were characterized by different colors ranging from very light yellow to dark orange, the specimens were both opaque and transparent.

Archaeological and artistic samples Table 2 lists the archaeological and historical samples. Figure 6 and Figure 7 show the Fibula 42 and The Fountain, respectively.

Chemicals hexamethyldisilazane (HMDS) was purchased from Sigma Aldrich (Milan, Italy).

\section{Methods and instrumentation}

For the Py(HMDS)-GC/MS analysis, the sample $(<0.1 \mathrm{mg})$ was placed in a quartz tube (held in place by glass wool), admixed with $5 \mu$ l hexamethyldisilazane (HMDS) and pyrolysed at $480^{\circ} \mathrm{C}$ (pyrolysis time: 20s). The pyrolyser (CDS Pyroprobe 5000 series) was coupled online with a 6890 N GC System Gas Chromatograph (Agilent Technologies, Palo Alto, CA, USA) coupled with a 5973 Mass Selective Detector (Agilent Technologies, Palo Alto, CA, USA) single quadrupole mass spectrometer. The pyrolyser interface was kept at $280^{\circ} \mathrm{C}$, the transfer line at $300^{\circ} \mathrm{C}$, and the valve oven at $290^{\circ} \mathrm{C}$. For the gas chromatographic separation, an HP-5MS fused silica capillary column (5\% diphenyl-95\% dimethyl-polysiloxane, $30 \mathrm{~m} \times 0.25 \mathrm{~mm}$ i.d., J\&W Scientific Agilent Technologies, USA) with a deactivated silica pre-column $(2 \mathrm{~m} \times 0.32 \mathrm{~mm}$ i.d., J\&W Scientific Agilent Technologies, USA) was used. The splitsplitless injector was used in split mode at $300^{\circ} \mathrm{C}$, with a split ratio of 1:10. The chromatographic conditions were as follows: $40^{\circ} \mathrm{C}$ isothermal for $5 \mathrm{~min}, 15^{\circ} \mathrm{C} / \mathrm{min}$ up to $300^{\circ} \mathrm{C}$ and isothermal for $25 \mathrm{~min}$. The carrier gas (He, purity $99.9995 \%$ ) was used in the constant flow mode at $1.0 \mathrm{~mL} / \mathrm{min}$.

\section{Competing interests}

The authors declare that they have no competing interests.

\section{Authors' contributions}

MPC conceived and coordinated the study, and helped to critically draft the manuscript. ER carried out theMS data interpretation and helped to draft the manuscript. MR performed part of the chemical analyses PS performed part of the chemical analyses and helped to draft the manuscript. All authors read and approved the final manuscript.

\section{Acknowledgements}

The Museo di Archeologia e Scienze Naturali G. Zannato (Montecchio Maggiore, Vicenza, Italy), Prof. Barbara Kosmowska-Ceranowicz (Museum of the Earth of Polish Academy of Sciences, Warsaw, Poland) and Museo Civico di Storia Naturale (Milan, Italy) are kindly acknowledged for providing geological succinites. The authors would also like to thank Dr. Nora Marosi (Studio Art Centers International, Florence, Italy), Dr. Maria Sframeli (Museo degli Argenti, Florence, Italy), Dr. Carlotta Cianferoni (Soprintendenza per i Beni Archeologici della Toscana), Dr. Marina Micozzi(Univeristà della Tuscia, Viterbo) and Prof. Jack Davis and Dr. Sharon Stocker (University of Cincinnati, USA) for providing the archaeological and historical ambers.

This work was partially financially supported by Regione Toscana and

Marwan Technology within the ALMA project under Bando Unico R\&S 2008, POR-CREO 1.5, prog. No. 2009DUA000000000016676205020000000002.

Received: 15 January 2013 Accepted: 28 February 2013

Published: 3 April 2013

\section{References}

1. Anderson KB, Crelling JC: Amber, Resinite and Fossil Resins. Washington, DC: Oxford University Press; 1995.

2. Lambert JB, Santiago-Blay JA, Anderson KB: Chemical signatures of fossilized resins and recent plant exudates. Angew Chem Int Ed Engl 2008, 47:9608-9616.

3. Tonidandel L, Ragazzi E, Traldi P: Mass spectrometry in the characterization of ambers, II Free Succinic acid in fossil resins of different origin. Rapid Commun Mass Spectrom 2009, 23:403-408.

4. Serpico M, White R: Ancient Egyptian Materials and Technology. In Edited by Nicholson P, Shaw I. Cambridge: Cambridge University Press; 2000:390-429.

5. Anderson KB, Botto RE: The nature and fate of natural resins in the geosphere-III. Re-evaluation of the structure and composition of Highgate Copalite and Glessite. Org Geochem 1993, 20:1027-1038.

6. Angelini I, Bellintani P: Archaeological ambers from northern Italy: an FTIR-DRIFT study of provenance by comparison with the geological amber database. Archaeometry 2005, 47:441-454.

7. Brody RH, Edwards HGM, Pollard AM: A study of amber and copal samples using FT-Raman spectroscopy. Spectrochimica Acta Part A 2001, 57:1325-1338.

8. Clifford DJ, Hatcher PG, Botto RE, Muntean JV, Michels B, Anderson KB: The nature and fate of natural resins in the geosphere-VIII. NMR and Py-GC-MS characterization of soluble labdanoid polymers, isolated from Holocene class I resins. Org Geochem 1997, 27:449-464.

9. Cunninham A, Gay ID, Oehlschlager AC, Langenheim JH: $13 C$ NMR and IR analyses of structure, aging and botanical origin of dominican and mexican ambers. Phytochemistry 1983, 22:965-968.

10. Guiliano M, Asia L, Onoratini G, Mille G: Applications of diamond crystal ATR FTIR spectroscopy to the characterization of ambers. Spectrochimica Acta Part A 2007, 67:1407-1411. 
11. Jehlika J, Jorge Villar SE, Edwards HGM: Fourier transform Raman spectra of Czech and Moravian fossil resins from freshwater sediments. J Raman Spectroscopy 2004, 35:761-767.

12. Lambert JB, Poinar GO: Amber: the Organic Gemstone. Acc Chem Res 2002, 35:628-636

13. Lambert JB, Tsai CY-H, Shah MC, Hurtley AE, Santiago-Blay JA: Distinguishing Amber and Copal Classes by Proton Magnetic Resonance Spectroscopy. Archaeometry 2012, 54:332-348.

14. Lydzba-Kopczynska Bl, Gediga B, Chojcan J, Sachanbiński M: Provenance investigations of amber jewelery excavated in Lower Silesia (Poland) and dated back to Early Iron Age. J Raman Spectrosc 2012, 43:1839-1844.

15. Shashoua Y, Degn Berthelsen M-BL, Nielsen OF: Raman and ATR-FTIR spectroscopies applied to the conservation of archaeological Baltic amber. J Raman Spectrosc 2006, 37:1221-1227.

16. Teodor ES, Teodor ED, Virgolici M, Manea MM, Truică G, Lițescu SC: Nondestructive analysis of amber artefacts from the prehistoric Cioclovina hoard (Romania). J Archaeol Sci 2010, 37:2386-2396.

17. Truică GI, Teodor ED, Litescu SC, Radu GL: LC-MS and FT-IR characterization of amber artifacts. Cen Eur J Chem 2012, 10:1882-1889.

18. Winkler W, Kirchner EC, Asenbaum A, Musso M: A Raman spectroscopic approach to the maturation process of fossil resins. J Raman Spectrosc 2001, 32:59-63.

19. Winkler W, Musso M, Kirchner EC: Fourier transform Raman spectroscopic data on the fossil resin siegburgite. J Raman Spectrosc 2003, 34:157-162.

20. Anderson KB, Winans RE: Nature and fate of natural resins in the geosphere. 1. Evaluation of Pyrolysis-Gas Chromatography / Mass Spectrometry for the analysis of natural resins and resinites. Anal Chem 1991, 63:2901-2908.

21. Colombini MP, Modugno F, Ribechini E: Archaeometric data from mass spectrometric analysis of organic materials: proteins, lipids, terpenoid resins, lignocellulosic polymers and dyestuff. In Mass Spectrometry Handbook Edited by Lee M. Hoboken, NJ, USA: J. Wiley \& Sons; 2012:797-828.

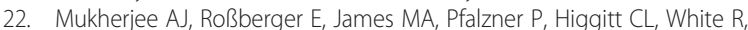
Peggie DA, Azar D, Evershed RP: The Qatna lion: scientific confirmation of Baltic amber in late Bronze Age Syria. Antiquity 2008, 82:49-59.

23. Poulin J, Helwing K: Class Id resinite from Canada: A new sub-class containing succinic acid. Org Geochem 2012, 44:37-44.

24. Anderson $\mathrm{KB}$, Winans RE, Botto RE: The nature and fate of natural resins in the geosphere-II. Identification, classification and nomenclature of resinites. Org Geochem 1992, 18:829-841.

25. Rocchi M, Ribechini E, Deviese T, Colombini MP: Identifying the characteristics of fossil resins (from Polish and Italian collections) using gas chromatography and mass spectrometry, Amberif 2009, Gdansk, Polonia. 2009.

26. Bonaduce I, Andreotti A: Py-GC/MS of Organic Paint Binders. In Organic Mass Spectrometry in Art and Archaeology. Edited by Colombini MP, Modugno F. Chichester, UK: John Wiley \& Sons; 2009:304-326.

27. Doménech-Carbó MT, de la Cruz-Cañizares J, Osete-Cortina L, DoménechCarbó A, David H: Ageing behaviour and analytical characterization of the Jatobá resin collected from Hymenaea stigonocarpa Mart. Int J Mass Spectrom 2009, 284:81-92.

28. Virgolici M, Petroviciu I, Teodor E, Litescu S, Manea M, Ponta C, Niculescu G, Costel S, Medvedovici A: TD/CGC/MS and FT-IR Characterization of Archaeological Amber Artefacts from Romanian Collections (Roman Age). Rev Roum Chim 2010, 55:349-355.

29. Vîrgolici M, Ponta C, Manea M, Daniel N, Cutrubinis M, Moise I, Suvaila R, Teodor E, Sârbuc C, Medvedovici A: Thermal desorption/gas chromatography/mass spectrometry approach for characterization of the volatile fraction from amber specimens: A possibility of tracking geological origins. J Chromatogr A 2010, 1217:1977-1987.

30. Tonidandel E, Ragazzi G, Roghi P, Tonidandel L, Ragazzi E, Roghi G, Traldi P: Mass spectrometry in the characterization of ambers. I Studies of amber samples of different origin and ages by laser desorption ionization, atmospheric pressure chemical ionization and atmospheric pressure photoionization mass spectrometry. Rapid Commun Mass Spectrom 2008, 22:630-638.

doi:10.1186/2050-7445-1-6

Cite this article as: Colombini et al: Analytical pyrolysis with in-situ silylation, Py(HMDS)-GC/MS, for the chemical characterization of archaeological and historical amber objects. Heritage Science 2013 1:6.

\section{Publish with ChemistryCentral and every scientist can read your work free of charge \\ "Open access provides opportunities to our colleagues in other parts of the globe, by allowing anyone to view the content free of charge." \\ W. Jeffery Hurst, The Hershey Company. \\ - available free of charge to the entire scientific community \\ - peer reviewed and published immediately upon acceptance \\ - cited in PubMed and archived on PubMed Central \\ - yours - you keep the copyright \\ Submit your manuscript here: \\ http://www.chemistrycentral.com/manuscript/ \\ () \\ Chemistry Central}

